\title{
SEX AND RELATIONSHIPS EDUCATION: HOW CAN CHILDREN WITH LEARNING DISABILITIES BE A PART OF IT?
}

\author{
Konstantina Spyropoulou ${ }^{\mathrm{i}}$ \\ MA, Med, University of Nottingham, \\ United Kingdom \\ Special Education Teacher, \\ Ministry of Education and Religious Affairs,
}

Greece

\begin{abstract}
:
Reflection constitutes a way of turning our experience into learning. A reflective journal will successfully link the theory with personal experience through an interactive interpretation of reflected knowledge. My background experience as a trainee teacher for a boy with mild learning disabilities in my placement was about an incident related to Sex and Relationships. This occurrence constituted the starting point of my personal learning experience. Knowledge is the "weapon" you can use to overcome any barriers and evaluate actions and relationships. This essay focuses on the sexuality and the provision of Sex and Relationships Education (SRE) that children with Learning Disabilities (LD) receive in countries around the world and the objectives of SRE. Moreover, children with LD, through the benefits of adequate education, can recognise their sexual identity, fight for their needs and rights and eliminate undesirable consequences. Lastly, this assignment will support my professional practice that will not only try to ameliorate children's educational lives but also empower my teaching skills in any similar situation in the future.
\end{abstract}

Keywords: reflective journal, experiential learning, aims and provision of SRE, learning disabilities, sexual abuse

\section{Introduction}

Learning constitutes the dominant element of human adaptation (Kolb, 1984) that can be created through experiences. The essential role of experience in human learning had been already recognized by J. Dewey, K. Lewin and J. Piaget during the $20^{\text {th }}$ century. Kolb, based on their theories created his theory of experiential learning. He used a learning circle that depicts a flow that goes from one process to another starting with the

i Correspondence: email konstantinapaidagogos@gmail.com, spyropoulou.k93@gmail.com 
experience, then the observation, afterwards the abstract conceptualisation and finally the implementation of new knowledge (Appendix A).

Reflection is a learning tool that promotes professional education and enables the investigation of knowledge for practice (Lyons, 1999). "If knowledge is power, then knowledge about who we are and how we practice is even more powerful" (p.34) (ibid). The module of "Relationships and Behaviour" was focused on experiential and reflective learning and personal, social and emotional development. For that reason, this task aimed to combine our concepts with a past personal experience and our learning during the course in a reflective way.

The tool that would enable us to attempt this reflection is a journal. Journaling has been claimed as one of the most powerful learning experiences (Yonge and Myrick, 2000). A learning journal is a "vehicle for reflection" (p.1) and a "place" (p. 82) where writers can be themselves (Moon, 2006). Vygotsky (1986) also described it as a vehicle for inner dialogue that links thoughts, feelings and actions with understanding. It can also serve as a "mirror" (p. 61) that reflects our hearts and minds (Hubbs and Brand, 2005).

When I first thought about how I would approach and write this reflective journal I felt like Joanna Field (1952 cited in Moon, 2006).

"I try to observe my own experience and discover that the more I look the more I see But I do not know how to learn from what I see." (p. 7)

It was my first time I was going to keep a journal. Mixed feelings inundated me...

"I never thought that the word "reflection" could be so new and intimidating to me, but at the same time so challenging. In the beginning, I said to myself "How difficult is it going to be? You will only have to write down your thoughts"! I thought that it looks like soul searching. Then I asked myself "Am I ready to testify with honesty and dignity what happened?" but mainly "Am I ready to realise my weaknesses and amend my mistakes?" (Reflective Journal, 25 January 2016).

Journaling has been also characterised as a risk-taking activity in terms of ethics for all of the participants (Yonge and Myrick, 2000). It is my responsibility to be aware, as a researcher, of ethical considerations. Based on BERA ethical guidelines (2011), educational research should be conducted with respect and trust to protect the identities and looking after others. Anonymity will be used to preserve child's confidentiality. The act of self-disclosure, if not used properly, can cause problems to researchers who express their personal experience. Those who are revealed in an open liberal discussion are more exposed to the fear of feeling "naked". Individuals must feel comfortable and keep asking themselves "How risky does it feel?". Therefore, the key phrase for selfdisclosure is appropriate self-disclosure and the key element for its prevention is the careful balance between risk-taking and self-care (Yonge and Myrick, 2000). 
My reflection was found in the session of SRE on the $14^{\text {th }}$ of March that motivated and reminded me of a unique experience that I had back in Greece. Feelings of shame, embarrassment, and fear made me hide this experience, although it was impossible to forget it. This session gave me "food for thought" and encouraged me to think of the ongoing debate between values, beliefs, attitudes, equity, equality, human needs and rights. Being influenced by these thoughts and in combination with my experience, the following question formed in my mind: "Can children with LD be properly educated in sexual relationships by overcoming the barriers of the inadequate provision of SRE"? By having this on my mind, I was ready to answer it and move on to the next step of my reflective exploration.

Therefore, two parts will constitute this exploration. The first will comprise extracts of my journal which will blend my past experience with my current knowledge about a boy with mild LD and the issue of contraception. Then, concepts of sexuality and learning/intellectual disabilities as well as myths and facts around sexuality will be discussed. The aims and the responsible people for the provision of SRE will be also mentioned. Moreover, the provision of SRE in different parts of the world will be analysed along with the detrimental results of insufficient information and the impact of the barriers. In the second part, implications for practice and proposals about professional support that will provide children with appropriate knowledge and opportunities in the future will be discussed.

\section{Part one: Learning Journal and Reflection and discussion of theory and literature}

\subsection{Past experience}

As it has been mentioned before, the session of SRE kept my interest alive in exposing my personal experience and exploring this field in more depth.

"It's challenging to write and reflect on your thoughts about something that you have not been educated in at school. Taboo, fear and shame about SRE didn't allow us to define ourselves around sex and sexuality. But why did education not instill in us this important value of knowledge? If not education, then who is more responsible for this training? It seems that, until now, no one could take the responsibility to inform us properly about Sex and Relationships." (Reflective Journal, 14 March 2016)

Through the exercise "GETs and GHASTLIEs" that took place during this session and the following discussion, it was easier for me to think further about the importance of respecting other's preferences without judging, teasing, and trying to stereotype because of the differences between us. Also, I realized how much we would all need to feel comfortable and respected in a school environment.

The session aimed to analyse the role that an educator has to adopt in teaching SRE to students with special needs. The conclusion of this session focused on the adequate training and knowledge of educators to accept, assist and guide children 
through the path of sex education; identifying their sexuality, creating healthy sex relationships between other individuals and succeeding in elimination of barriers, discrimination and abuse.

My experience was closely related to an incident that showed a lack of awareness and educational provision around sex and relationships. One day, the boy came to me during the break, holding a condom that he found in the school-yard and asked me "Can you help me to blow up this balloon Miss?" and he almost put the condom in his mouth.

"I was shocked! Really? Is this happening to me? I wondered. How could I explain to him that this was not a balloon but a condom and that the use of condoms is for preventing sexually transmitted diseases? Should I also explain what is "sex" and "transmitted diseases" or much more terms that would probably arise? For sure I wasn't trained to teach all these meanings, because I didn't receive any relevant education as a student neither from teachers nor parents. So, I grabbed the condom and told him not to use things he finds on the floor because they are dirty, have been already used by others and we cannot use them again. I didn't take the responsibility to tell him the truth under these circumstances, because I have never discussed with him about sex. For that reason, it would be extremely difficult without any supportive material to explain during the break what a condom is. I keep asking myself if this was the right decision. I'm sure it wasn't but then I tried to reassure myself by thinking that I have only been in this school just for 3 months for my placement and probably the teacher should be the most suitable person for teaching SRE. However, is it right to pass the responsibility to someone else? Even if I wasn't experienced enough should I have explained it to him?" (Reflective Journal, 14 March 2016)

A role-playing game towards the end of the session and the upcoming discussion helped me to conquer my barriers and defy my shame that has "blurred" my mind and made me an idle person. In groups of two, there was one educator and one student. The student posed a question that s/he had when s/he was 14 years old and the educator had to answer it. The roles of educators and students were exchanged between us.

"That moment, having the teacher's role, I remembered all over again this awkward incident with my student, but at the same time, when I became a student, I felt like I was in his shoes. How weird is it to live in ignorance?" (Reflective Journal, 14 March 2016)

At that point by closing this session, I realised the responsibility I have towards my students by not bereave them again of the right to learn about Sex and Relationships.

"I think I realized that the only thing I was lacking was self-esteem. I will never be ashamed again! From this session, I learned that there are age-appropriate responses and we must be honest with children by finding the appropriate means and language to express what we want to teach them. The key point is not only to educate and raise their awareness but also 
to guide them with support and sound pieces of advice." (Reflective Journal, 14 March 2016).

From that moment on, I am sure I am more ready than ever to learn more about SRE and face any kind of situation that might arise.

\subsection{Understanding the terms}

There is a huge controversy between the terms "learning disabilities/difficulties" and "intellectual disabilities". Learning disability/difficulty is commonly used in the UK to describe a person with a limited intellectual ability to understand complex information or learn new skills, which has lasting effects on social functioning, behaviour and development (Department of Health, 2001). On the other hand, in other English-speaking countries, the term "intellectual disability" is growing in usage and is commonly used to describe what is understandable in the UK as LD. However, this clarification takes place to understand the diversity of terminology and not focus on people's discrimination based on their disability.

Next, the terms of "sexuality" and "Sex and Relationships Education" will be identified. Sexuality constitutes a key dimension of human existence (Biddulph, 2012) which is inextricably interwoven with self-esteem and self-development (Barboudi, 2012). Sexuality is also a moral and political arena of a continuous debate (Biddulph, 2012) and can influence positively the emotional, psychological, ethical, cultural, physical and social identity of individuals.

Sex Education is such a broad field that has its base in the knowledge of physiology, biology and reproduction (Measor et al., 2000). However, it is deeper than that, as, in recent years, SRE is lifelong learning that incorporates broader subjects of sexuality, interpersonal relationships, sexual health and development, love, affection and familiarity with the function of the body (Swango-Wilson, 2008; Barboudi, 2012). SRE embodies the elements of knowledge and information, personal and social skills, attitudes and values and emotions focused on identity and self-esteem (Blake and Laxton, 1997) (Appendix B).

\subsection{Dispelling the Myths and reinforcing the facts}

Historically the sexuality of children with LD was denied and suppressed. Particularly with the eugenics movement between 1880 and 1940, sterilisation and segregation in asylums and institutions were implemented. These children, who tend to call them as mentally "defective" (p. 95) (Kempton and Kahn, 1991), were also believed to be asexual, only heterosexual or hypersexual, with criminal behavior, something that was supported by the studies of Jukes and Kallikaks. From 1907 to 1957 almost 60,000 persons with LD were sterilized without their consent (Paul, 1974 cited in Kempton and Kahn, 1991). Research studies conducted in 1925 showed that patients who had been sterilised became infertile and criminal behavior arose from any other reason except LD (Kempton and Kahn, 1991). Until 1973, 23 states still permitted the law of involuntary sterilisation 
(ibid). Still, in 1990, Special Education Teachers' majority supported sterilisation for children with LD (Wolfe, 1997 cited in Ailey et al., 2003).

More recently, a survey found that men with LD had been sterilised even if they did not present inappropriate sexual behaviour or interests in sexual activities (Carlson et al., 2000). Also, they tend to believe that children with LD have a childlike appearance and behavior, something that made them sexually unappealing and unable to attract sexually other partners (Addlakha, 2007 cited in Gomez, 2012). There was also a false perception that if people become sexually educated, they will be more vulnerable to abuse or become sexual offenders (Hamilton, 2009).

Fortunately, positive results have been produced by 1950. The era of sexual revolution along with the civil rights movement (1960) acted as catalysts for a better life by achieving normalisation of educational programs and deinstitutionalisation of people with LD (Kempton and Kahn, 1991). From 1970 until today, through acts and legislations, the assertion of sexual rights is a fact. Access to knowledge for sexuality and SRE is equal for all students and the education of parents is also essential. Today surveys reject the aforementioned myths and prove not only are they not aggressive but are passive and chasing for love and affection (Tsinos, 2011).

The creation of formal SRE programs has become indispensable. Collaboration between parents and educators can help students make good choices and avoid risky behavior (Boehning, 2006). Teachers should bear in mind students' individual needs, by differentiating the materials and the ways of teaching them. Subjects that arose from the literature and should be included in SRE might be sexual health, sexual transmitted diseases and AIDS, exploring body parts, sexual intercourse, gender, public/private places, masturbation, menstruation, sexual orientation, dating and intimacy, contraception, marriage, sexual pleasure, sexual attack, sexual abuse and harassment, sexual exploitation/feelings/relationships, life cycle, decision-making and assertion (Sex Education Forum, 2001; Barboudi, 2012).

There are also some cases of teachers and parents who still tend to believe their children are unable to feel sexual urges and overprotect them. For example, staff teaching members expressed reasons for not teaching SRE based on false beliefs (Schaafsma et al., 2014). The reasons were that children were not sexually active yet; they did not want to receive the SRE and did not have the equivalent skills. Parents' stances tend to be conservative about SRE as well. Kupper (1994) advised parents to not be afraid of not awakening children's feelings of sexuality because these feelings already exist in every single person.

\subsection{Sex and Relationships Education: Objectives and Education bodies}

Overall, SRE is an education that protects human rights and provides children the chance to be sexually expressed and experienced and feel accepted and safe (Ailey et al., 2003). Sexuality begins at birth. Young people must have access to SRE as soon as possible.

Children with LD have the same physical and biological development as their peers (typical development) (Carter, 1999; Karamanou et al., 2013). That means that they 
need to receive the same content, but with different methods and materials based on their necessities regarding the type and severity of disability (Carter, 1999). SRE should not be taught reactively but for preventing an undesirable condition (Schaafsma et al., 2015), such as transmitted infections, pregnancies, sexual abuse, vulnerability, and exploitation. SRE programs can offer a variety of benefits to children with LD. First of all, children can ameliorate their sexual well-being to adjust gradually in the community (Sex Education Forum, 2003; Swango-Wilson, 2008) and become selfprotected. Moreover, through SRE, children can learn to express their needs, communicate with others, and be developed socially and emotionally (Sex Education Forum, 2003).

Children should also become educated in creating healthy relationships with others. Components of a healthy relationship are considered mutual respect, trust, honesty, reciprocity, acceptance, equality and reliable alliance (Roffey, 2011). A good teacher has to support, encourage, listen, accept, trust, respect, and negotiate with pupils, rather than criticise, blame, complain, threaten, punish and bribe (ibid). Regardless of age, gender, culture, ability, faith, and sexual preferences, children need to know how to control and cope with their sexuality, sexual feelings and urge and this is one more reason that makes SRE essential for them (Sex Education Forum, 2004).

Educators, parents, and other sex professionals are the educational bodies who are responsible for teaching SRE. Parents and careers are considered the first role models for children. Then, teachers, educators and other professionals follow by playing a major role in children's healthy sex development and sound edification.

Both educators and parents face a great number of difficulties for the implementation of SRE. Some of them are anxiety, concern and fear. As a result, they avoid informing and educating their children about sexuality issues. That is happening because some of them do not know how to start and handle a situation. They do not take the responsibility of talking and dealing with sexuality issues, whereas others believe that a discussion might encourage children to be sexually active before the appropriate time or learn more than they should have known.

Mass media and peers are the unofficial sources of information from which children receive sexual messages during school years. "The media portray the views of society." (p.281) (Gougeon, 2009). Mainly television and during the last few years internet do not include people with LD. Even if they rarely do so, they focus first on the disability, then on the personality and lastly on sexuality. This is something that enhances society's misunderstandings and confusions about individuals with LD (ibid). As a consequence, peers have been influenced by the media's and society's beliefs and tend to adopt a negative opinion towards them.

"... if I were in his shoes I would need to know some things about sex, as I've got the same desire when I was in his age. The source of my knowledge was only peers and media that most times made me believe in mistaken and misleading views about sex". (Reflective Journal, 14 March 2016) 


\subsection{Sex and Relationships Education provision}

This part will examine the provision of SRE for children with LD in different parts of the world and will report the main factors that impede children's adequate education. Negative attitudes towards sexuality come as a result of people's sexual needs that are "frequently being ignored...curtailed or actively denied by professionals as well as the general community" (p.206) (Szollos and McCabe, 1995 cited in Fitzgerald and Withers, 2011).

Historically, people with LD were discouraged and impeded from developing relationships and let alone having sex or expressing their sexuality in any way. Parents and teachers were afraid that if SRE becomes available to them, they will be sexually or hyper-sexually active and this will also lead to sexual abuse. Present-day, some countries have accepted SRE, whereas others are still under the fear of SRE and maintain conservative views towards it.

In a comparative study, parents' and teachers' views about SRE were investigated in Stockholm and Tokyo. In Stockholm, as a result of having compulsory SRE, children were more informed than those in Tokyo. Also, parents and teachers showed more positive attitudes in contrast to Tokyo and found it easier to discuss sex issues (Katoda, 1993). Apart from the delay of SRE and the adverse teachers' beliefs about children's sexuality, the educational system in Tokyo is also heterosexually centered, by forgetting about homosexual children (Hayashi et al., (2011).

In a Nigerian study, the results showed that teachers' perspectives about the sexuality of children with LD were also negative, as they mainly consider them as "hypersexual" and unable to have sexual relationships. Misconception and a lack of teachers' skills explain why there is no SRE curriculum in Nigeria. That raises the risk of sexually transmitted diseases, abuse and impedes effective SRE implementation (Aderemi, 2014).

In Ireland, carers, support and professional staff stated that they did not feel ready to undertake SRE, because of people's cognitive and communication impairments, shame and a lack of resources and materials, even though they were found available (Lafferty et., 2012). Apart from that, Ireland is a place where homosexual relationships are not the "taboo" (p. 910) as in other countries because television promotes gay and lesbian people (Healy et al, 2009) and SRE has been mandatory already from 2003 (Parker et al., 2009).

In developing countries, such as Mexico, for many years, sexuality for individuals with LD meant sterilisation and constituted part of programs (Katz and Lazcano-Ponce, 2008). Presently, although there has been some progress, the care for people with LD is still limited, as some teachers still consider children with LD as asexual (ibid). Overall, Norway and Denmark are considered the first countries that supported people's sexual needs, and teachers are obliged to provide SRE (Parker et al., 2009). Also, countries such as the Czech Republic, Finland and Netherlands have a consistent and mandatory SRE, where religion does not constitute an influence in teachers' teaching, similar to France and Germany where there is generally a good level of teaching. In contrast to them, Bulgaria, Cyprus, Greece, Hungary, Italy, Latvia and Spain are mostly influenced by religion, and still, in most of them, SRE is not a mandatory subject. Also, there is 
insufficient relation to SRE from teachers in school contexts and parents at home (ibid). Having all these facts in my mind, I wondered:

"How is it possible for teachers, professionals and educators to be so reluctant to provide SRE to children with LD? How can educators avoid the fact that all students are equal and have the right to be properly educated in school environments? Education should be at the forefront of student's needs! Can teacher's fear and embarrassment cover children's needs?"(Reflective Journal, 14 March 2016)

The lack of adequate training certainly constitutes one of the major issues that make teachers unable to provide SRE. However, views and beliefs that have been constructed by society's stereotypes should not affect teacher's treatment of children with LD.

On the other hand, as previously discussed, parents are another obstacle that inhibits the implementation of SRE. Some believe that teachers must be the only ones responsible for SRE, whereas others do not agree with this kind of education for their children or do not consider teachers as qualified.

"I have noticed that parents sometimes might be "blind" and cover their ears not to hear the voices from the "outside" world by letting overprotection and pathological love outweigh the reality and facts. A conservative stance has been also adopted by a boy's mother two days after the incident, as she told the school teacher that she found some love letters with drawings in his bag that they were for a girl from the school. She asked to keep an eye on him in order to prevent him from approaching this girl. I felt really weird! Why did she act like that? It is not normal to feel attraction and have innocent feelings of love at this age? Why parents should prevent children from expressing these feelings or they think that the disability can cover any other aspect of children's lives? Cannot they understand that the lack of awareness around SRE could be proven detrimental for their physical and emotional lives in the future?" (Reflective Journal, 14 March 2016)

Additionally, the issue of SRE is further complicated because of religion and culture that most times seem to be interrelated. Ethical issues are opposed to SRE aims. Many families and teachers get influenced by these beliefs by neglect children's need for SRE. Culture through stereotyping and stigmatizing marginalise people with LD as the "waste" of the society that is unable to operate functionally with the rest of the people. My point of view is that SRE does not contradict our faith. It actually raises children's awareness about sex-related issues and constitutes a source of prevention from undesirable conditions, such as diseases, pregnancies, abuse, discrimination and bullying and allows them to make sound decisions. 
All these outcomes suggest that further education on SRE must be provided for people with LD. Based on the literature, surveys indicated that the provision of SRE is disappointing in schools and effective measures should be implemented immediately.

\subsection{Identifying and overcoming the barriers resulting from the lack of Sex and Relationships Education's provision in children with Learning Disabilities}

Some of the barriers and most importantly lack of appropriate education increase the incidents of sexual abuse and cause high risks of sexual harassment and discrimination towards children with LD.

Sexual abuse can cause psychological and mental health problems such as anxiety, depression (Bennett and Bauman, 2000; Eastgate et al., 2011), impaired self-esteem, alienation and it can also make children drop out of school (Bennet and Bauman, 2000).

Surveys have found that children with LD are being sexually abused 4 times more than their normal peers. $79 \%$ of women and $54 \%$ of men have been sexually harassed. The majority of the abusers were relatives or close family members (Stromsness, 1993 cited in Barboudi, 2012). Also, another study found that women barely recognize the act of abuse and even if they did, they are discouraged from telling it (Swago-Wilson, 2008). Moreover, sexual abuse or rape can cause problems in people's health and physical condition.

Therefore, to my mind, awareness about sexually transmitted diseases, contraception, and the capacity to consent or not to sexual relationships cannot be developed if education does not exist or does not include children with LD.

We should all first wonder ourselves "Why are people with LD so vulnerable to sexual abuse?" and "How can the severity of impairment have an impact on the vulnerability of the potential victim?" The overprotected lives not only do not let them develop their skills of independence but also do not allow them to take responsibilities and decisions about their lives.

"As I join the pieces of this "puzzle" in my mind, I remember that most of the time he came to walk or play with me during the breaks. Now, I can see his need to feel that he has friends. He did not have any friends at his age and this fact explains also why his social skills were so poor. I was trying to encourage him to go and play with their peers but he did not want to. How he could do that if it was the lack of self-esteem that made him flinch and feeling incapable of engaging in any kind of relationship with the others? How will he approach or be approached by others?" (Reflective Journal, 14 March 2016)

As a result, limited social chances and social interactions can lead to undesirable outcomes and wrong interpretation of someone's intention. Ignorance of danger, signs and symptoms of abuse, denial and non-disclosure to others can lead to the coverage of sexual abuse and its continuity in time.

As Sequeira (2006) reports, if it is not possible to have an earlier intervention, postabuse can act as a deterrent from the establishment of chronic symptoms. She also stresses 
the importance of recognising and revealing the source of symptoms because otherwise, an ongoing abuse will remain undiscovered.

Some effective methods of protection from sexual abuse are children learning how to have a voice and speak up for enhancing their self-advocacy, something that leads to the enhancement of self-protection skills. Furthermore, children need someone to support them and rely on their concerns and problems.

To conclude, based on the studies, it is apparent that children with LD have the same right to receive SRE and accomplish the targets of self-development as equal human beings. Support and encouragement of parents, caregivers, staff and teachers play a major role in enhancing their self-esteem and build the basis for healthy Sex Relationships and normal sexual life without fears and restrictions. Otherwise, all the negative effects might lead to the false belief that they deserve the exploitation and abuse as a consequence of their disabilities. The only thing that remains to be found is a "medium between the expression of sexual human rights and the protection from undue harm" (p.282) (Gougeon, 2009).

\section{Part two: Changing children's future: Implications for professional practice - Intentions and plans}

Based on my experience, I have learnt not to be reluctant again and use my knowledge to approach and deal with any relevant incident that might arise in the future, thanks to the session "Sex and Relationships Education".

Keeping a learning journal based on your exploration of past experiences and evaluating the possible impact that they had on your personal and professional development could be very effective for the improvement of your practice in favor of your students. From now on, I will try not to hide or escape from my responsibility that I have as teacher on the grounds that SRE is a part of special needs education that I am willing to provide to my students. For this provision, it is important to find out what makes a good inclusive practice. As Parker et al., (2009) mention, inclusive SRE can act as one of the most powerful tools that enable students to be well informed and make sound choices.

Therefore, as a professional teacher, I am ready to transfer this learning to the classroom by searching, planning and implementing an appropriate SRE program for future practice.

\subsection{Teacher's preparation}

As a teacher, I would try to collaborate with parents by discussing and realising their attitudes, intentions and expectations toward SRE. Their perceptions constitute an important part of children's awareness and can help in enhancing children's development by providing many elements of children's sexuality and sexual life. In this way, parents will trust educators and will be more aware of SRE programs' aims that will benefit their children. 
All this information will make my task easier in organising the rest of my plan. By having in mind children's acquired knowledge, I will try to evaluate their needs and find an effective intervention program. The program should be flexible with structured sessions and easily adapted to children's needs according to their age, abilities, gender, sexuality and cultural background (Sex Education Forum, 2003). Moreover, collaboration with teaching staff and other professionals should be achieved in order for all to be aware of children's needs and privileges (ibid).

\subsection{Curriculum content}

Teachers must receive the necessary training in order to adapt to any situation that might arise in the classroom. So, my next step would be the identification of the most crucial topics that must be included.

First of all, a sound curriculum should cover issues related to self-development, such as self-concept and self-esteem. All these will start with children's awareness about their body and they will end up at their feelings. In this way, I will start a discussion on issues related to sexuality, sexual desires and sexual orientation.

Moreover, this program should address the fundamental lack of social skills and sexual knowledge that children with LD have. Self-protection skills can be taught for the promotion of children's social, emotional and sexual development. Lack of viable means of communication makes it difficult for the children to express themselves, as a result, sometimes this leads to alienation and exclusion (Gomez, 2012). Similar to my experience with this boy with LD, the use of simple language will enable him to communicate and discuss with other people, something that will improve his social skills in practice and will broaden their friends' zone.

Another important issue I would like to introduce is the exploration of body parts and the clarification of private and public places in terms of masturbation. An example would be a group activity where children with LD should focus on identifying the appropriate times and places (Dyke et al., 1998) for having sexual desire through masturbation (Appendix C).

Furthermore, issues such as sexual intercourse and contraception will follow. Contraception will be extensively analysed because it is a broad topic that can lead to undesirable pregnancies and transmitted diseases that constitute major social concerns nowadays. An appropriate example that could be proven suitable for my experience with that boy in the past is to teach children about contraception by starting a discussion related to condoms or birth-control pills. Then, I will stress that they should be taken sensitively and comprehensively (Bennett and Bauman, 2000) and this discussion can lead to the topic of safer sex activities and this in turn will end up in same-sex relationships (Craft et al., 1996). I will also include open and non-judgmental discussions about love and sexual desire and the normality of finding people from the same gender sexually attractive. 
Finally, I will talk about sexual abuse and discrimination, and I will teach them ways to recognize and report anything that makes them feel uncomfortable, as they have the right to deny if they do not want to yield to undesirable sex.

We are responsible, as teachers, to provide personal safety and protection (Northway et al., 2013), something that will lead to their optimal sexual health.

\subsection{Materials and tools}

Teaching could be organized in different ways, in which both pupils and staff must feel comfortable. The use of specially designed materials for children with LD should be carefully chosen in order to follow the pace of children's learning which will be based on their type of disabilities, their age and their reading level (Wolfe and Blanchett, 2003). First of all, audiovisual resources should be taken into consideration. I aim to use visual aids, such as pictures, that will represent "real" people in "real" situations as Grieveo et al., (2006) claim, as well as illustrations and symbol cards showing emotions that can be proven useful. Next, videos that will show personal sexual experiences and slides which should not be detailed will eliminate the possibility of distraction from the key points. Some potential slide issues might be sexual life circle, social-sexual behavior, relationships, sexual health and abuse, sexually transmitted diseases, marriage, body part identification, masturbation, puberty and intercourse.

Furthermore, role-play scenarios with case studies and quizzes, games with 3D models, drawings of people's body parts or designing of posters can prove effective for teaching children with LD in the future. For example, the use of drama or role-playing can be implemented as follows: One child can describe a situation and ask a student to step in front of the screen if he or she thinks that the situation is public, or step behind if it is private (Sex Education Forum, 2004). Another way to express drama is filming the role-play, then watching with the students and after discussing or mime what they saw during the film. Moreover, specialists around Sex and Relationships can visit our classroom to provide evidence that will support the information given to them. Visits to other places can be also a good way for children to see the implementation of some things in practice. Another example could be storytelling with pictures, artwork, puppets and a range of related activities (Garbutt et al., 2009). Puppets and dolls have the advantage that all children usually find it easy to put themselves in the roles of the opposite gender, as is mentioned in the Sex Education Forum, 2001. Additionally, books and leaflets must be written in a way in which everyone can understand the language. To my mind, all these techniques can be helpful instruments for introducing and practicing children's basic social skills as well as adopting appropriate behavior.

It is vital as well to set up some rules and ask children for their feedback at the end of each activity (Children's LD Nursing Team, 2009) (Appendix D). New forms of assessment tools and training resources have to be updated often to meet children's needs. Also, repetition is a way that learning can be fun and easily reinforced. Using stepby-step explanations and demonstrations, practice opportunities and positive reinforcement (Smith et al., 1995) can provide children with the most valuable tools for 
their sexual development. Therefore, I must respect the privacy and confidentiality of children, (Sex Education Forum, 2003) their confessions and stories and create an environment where they feel safe and secure.

Lastly, the process of learning for people with LD is slow and painstaking, for that reason support and encouragement play a major role in the achievement of comprehension and implementation of attitude change.

All the three aspects that are mentioned above are interrelated with each other and if they operate effectively, can contribute to the enhancement of self-development and the improvement of children's sexual lives.

\section{Conclusion}

The session of SRE motivated me to recall and reflect upon my personal experience in the past. The prior experience was the motivation that guided me to deal with a possible future experience. This exploration made me realise my weaknesses and find the strength to deal with sex-related issues by fighting my constraints, fear and embarrassment. Firstly, the terms of LD and intellectual disabilities as well as sexuality and SRE were identified. Then, myths and stereotypes that society disseminates contradicted the facts. The objectives and the people who are responsible to deliver the SRE were also examined. The inadequate provision of SRE for children with LD was reviewed and the outcomes of the lack of SRE and implications for future professional practice were also analysed. As it was made clear, many schools have total blindness in terms of the concept that sex is only for people without Special Educational needs. As a result, adolescents with LD are considered problematic, overestimated, or underestimated (Smith et al., 1995) and finally excluded.

Educators have the power to evaluate the curriculum of SRE and link student's needs with parents' expectations along with the selected material (Wolfe and Blanchett, 2003). In SRE social, moral and physiological aspects must be interrelated. Schools and teachers must be informed about pupils' needs to plan an appropriate program that enables children to increase their knowledge, explore attitudes and values and develop skills. All these will aid them to form sound relationships and make the right decisions regarding Sex and Relationships.

Children's inherent sexual rights must be accepted, supported and respected. Sexual-esteem can be increased if we encourage their sexual self-determinism through the enhancement of self-efficacy (Teleporos and McCabe, 2001 cited in Bernert and Ogletree, 2013).

Through my investigation, the initial question I posed found solid ground and started the conversation about the inadequate provision of SRE in schools for children with LD as well as the identification of its barriers.

Feasible solutions for a future professional practice that were proposed reinforced the possibility of children with LD to be totally accepted and appropriately educated in a school context. 
To conclude, keeping the reflective journal has given me a chance to gain a more spherical idea about my personal and professional identity by exploring my qualities through a challenging path and as Bassot (2013) said "I always knew I would learn a lot, but I never realized how much I would learn about myself" (p.x).

\section{Conflicts of interest}

The author declares that there are no conflicts of interest.

\section{Acknowledgements}

I would like to devote this space in order to thank the people who have contributed towards the completion of this assignment.

First of all, I would like to express my gratitude to all the professors of the MA Special Needs course (University of Nottingham) who inspired me as an educator and enlightened me to become a good researcher.

In addition, I would like to express my very great appreciation to my beloved parents and sister for their valuable financial and emotional support. Especially, I would like to thank my mother, whose endless love and patience were encouraging and supporting me to pursue my goals during this year.

Finally, I would like to thank my friends who believed in me and made this journey worthwhile during my studies at the University of Nottingham.

\section{About the Author}

Konstantina Spyropoulou was born in Volos (Greece). She studied at the Faculty of Preschool Education at the University of Thessaly where she received her Bachelor's Degree in 2015. She did postgraduate studies in the United Kingdom, where she got her Master of Arts Degree in the field of Special Education (2016) and she also got a Master in Education in the field of Intercultural Education (2018). Moreover, Konstantina is an undergraduate student at the National and Kapodistrian University of Athens in the sector of French Language and Literature. She obtains a qualified teacher status (QTS) in order to teach in a maintained school or non-maintained special school in England. She has worked voluntarily as a teacher/teaching assistant in the United Kingdom both in Special and Mainstream schools. In addition, she has been working in Greek public schools, as a Special Education Teacher, at the Ministry of Education since 2017, by supporting students with Special Educational Needs and behavioral problems with oneto-one teaching or/and group sessions. Moreover, Konstantina has been providing professional teaching support since 2015 to children with or without special needs as well as bilinguals, aged from 4 to 12 years old. She fluently speaks Greek, English and French. She possesses Braille certification and she knows the Greek Sign Language. She has participated in many seminars, conferences and educational programs. She has also gained many certificates of specialization in relevant educational sectors. Her research interests focus on the following: Teaching Methods in Preschool and Primary Education, 
Interventions in Special Education, Behavioral Management of students with autism, ADHD, psychological and social difficulties as well as Adaptation of bilingual students.

\section{References}

Aderemi, T. (2014). Teachers' Perspectives on Sexuality and Sexuality Education of Learners with Intellectual Disabilities in Nigeria. Sexuality and Disability 32(3): pp.247-258.

Ailey, S. H., Marks B. A., Crisp C. and Hahn J. E. (2003). Promoting sexuality across the life span for individuals with intellectual and developmental disabilities. Nursing Clinics North America 38(2): pp.229-252.

Barboudi, E. (2012). Sexuality and sex education of people with autism orland learning disabilities. A pilot survey for parents. Dissertation. University of Macedonia.

Bassot, B. (2013). The Reflective Journal. Capturing your learning for personal and professional development. Hampshire: Palgrave Macmillan.

Bennett, D. and Bauman, A. (2000). Adolescent mental health and risky sexual behaviour. BMJ 321(7256): pp.251-252.

Bernert, D. and Ogletree, R. (2013). Women with intellectual disabilities talk about their perceptions of sex. Journal of Intellectual Disability Research 57(3): pp.240-249.

Biddulph, M. (2012). Sexualities and citizenship education. In: Arthur, J. \& Cremin, H. (Eds.) Debates in Citizenship Education, p.100-114. London \& New York: Routledge.

Blake, S. and Laxton, J. (1997). Strides: A Practical Guide to Sex and Relationships Education with Young Men. London: fpa.

Boehning, A. (2006). Sex Education for students with disabilities. Law and Disorder (1): pp.59-66.

British Educational Research Association (BERA) (2001). Ethical Guidelines for Educational Research. Available at: https://www.bera.ac.uk/wpcontent/uploads/2014/02/BERA-Ethical-Guidelines-2011.pdf?noredirect=1 [Accessed 11 April 2016].

Carlson, G., Taylor M. and Wilson J. (2000). Sterilisation, drugs which suppress sexual drive, and young men who have intellectual disability. Journal of Intellectual and Developmental Disability 25(2): pp.91-104.

Gomez, M. (2012). The S Words: Sexuality, Sensuality, Sexual Expression and People with Intellectual Disability. Sexuality and Disability 30: pp.237-245.

Carter, J. (1999). Sexuality Education for Students with Specific Learning Disabilities. Intervention in School and Clinic 34(4): pp.220-223.

Craft, A., Stewart, D., Mallett, A., Martin, D. and Tomlinson, S. (1996). Sex education for students with severe learning difficulties. Health Education 96(6): pp.11-18.

Department of Health (2001). Valuing People - A New Strategy for Learning Disability for the 21st Century. Cmnd 5086. GOV.UK. 
Eastgate, G., Van Driel, L. M., Lennox, N. and Scheermeyer, E. (2011). Women with intellectual disabilities: A study of sexuality, sexual abuse and protection skills. Australian Family Physician 40(4): pp.226-230.

Fitzgerald, C. and Withers, P. (2011). 'I don't know what a proper woman means': what women with intellectual disabilities think about sex, sexuality and themselves. British Journal of Learning Disabilities 41(1): pp.5-12.

Garbutt, R., Tattersall, J., Dunn, J. and Boycott-Garnett, R. (2009). Accessible article: involving people with learning disabilities in research. British Journal of Learning Disabilities 38(1): pp.21-34.

Gougeon, N. (2009). Sexuality education for students with intellectual disabilities, a critical pedagogical approach: outing the ignored curriculum. Sex Education 9(3): pp.277-291.

Grieveo, A., McLaren, S. and Lindsay, W. (2006). An evaluation of research and training resources for the sex education of people with moderate to severe learning disabilities. British Journal of Learning Disabilities 35(1): pp.30-37.

Hamilton, C. A. (2009). Now I'd like to sleep with Rachael'-researching sexuality support in a service agency group home. Disability and Society 24(3): pp. 303-315.

Hayashi, M., Arakida, M. and Ohashi, K. (2011). The effectiveness of a sex education program facilitating social skills for people with intellectual disability in Japan. Journal of Intellectual and Developmental Disability 36(1): pp.11-19.

Healy, E., McGuire, B., Evans, D. and Carley, S. (2009). Sexuality and personal relationships for people with an intellectual disability. Part I: service-user perspectives. Journal of Intellectual Disability Research 53(11): pp.905-912.

Hubbs, D. and Brand, C. (2005). The Paper Mirror: Understanding Reflective Journaling. Journal of Experiential Education, 28(1): pp.60-71.

Karamanou, C., Petini, T. C. and Roussa, G. (2013). Learning Disabilities, Downs Syndrome and Social Impact. Dissertation. TEI of Ipiros.

Katoda, H. (1993). Parents' and teachers' praxes of and attitudes to the health and sex education of young people with mental handicaps: a study in Stockholm and Tokyo. Journal of Intellectual Disability Research 37(2): pp.115-129.

Katz, G. and Lazcano-Ponce, E. (2008). Sexuality in subjects with intellectual disability: an educational intervention proposal for parents and counselors in developing countries. Salud pública de México 50(2): pp.s239-s254.

Kempton, W. and Kahn, E. (1991). Sexuality and people with intellectual disabilities: a historical perspective. Sexuality and Disability 9(2): pp.93-111.

Kolb, D. A. (1981). Learning styles and disciplinary differences. The modern American college pp.232-255.

Kolb, D. A. (1984). Experiential learning: Experience as the source of learning and development (Vol. 1). Englewood Cliffs, NJ: Prentice-Hall.

Kupper, L. (1994). Teaching children and youth about sexuality. National Information Center for Children and Youth with Disabilities News Digest (1): pp.9-12. 
Lafferty, A., McConkey, R. and Simpson, A. (2012). Reducing the barriers to relationships and sexuality education for persons with intellectual disabilities. Journal of Intellectual Disabilities 16(1): pp.29-43.

Lyons, J. (1999). Reflective education for professional practice: discovering knowledge from experience. Nurse Education Today, 19(1): pp.29-34.

Measor, L., Tiffin, C. and Miller, K. (2000). Young Peoples' Views on Sex Education. Education, Attitudes and Behaviour. Routledge/Falmer, London.

Moon, J. A. (2006). Learning Journals. A handbook for reflective practice and professional development. $2^{\text {nd }}$ ed. New York: Routledge.

Northway, R., Bennett, D., Melsome, M., Flood, S., Howarth, J. and Jones, R. (2013). Keeping Safe and Providing Support: A Participatory Survey About Abuse and People with Intellectual Disabilities. Journal of Policy and Practice in Intellectual Disabilities 10(3): pp.236-244.

Parker, R., Wellings, K. and Lazarus, J. (2009). Sexuality education in Europe: an overview of current policies. Sex Education 9(3): pp.227-242.

Roffey, S. (2011). The power of positive relationships. In: Roffey, S. Changing behaviour in schools: promoting positive behavior and wellbeing, pp.100-119. London: Sage.

Schaafsma, D., Kok, G., Stoffelen, J. and Curfs, L. (2014). Identifying Effective Methods for Teaching Sex Education to Individuals with Intellectual Disabilities: A Systematic Review. The Journal of Sex Research 52(4): pp.412-432.

Schaafsma, D., Kok, G., Stoffelen, J., van Doorn, P. and Curfs, L. (2014). Identifying the important factors associated with teaching sex education to people with intellectual disability: A cross-sectional survey among paid care staff. Journal of Intellectual and Developmental Disability 39(2): pp.157-166.

Sequeira, H. (2006). Implications for practice: research into the effects of sexual abuse on adults with intellectual disabilities Journal of Adult Protection 8(4): pp.25-30.

Sex Education Forum (2001). Ensuring entitlement: Sex and relationships education for disabled children. Available at: http://www.ncb.org.uk/media/229350/ensuring entitlement sex and relationships education for disabled children.pdf [Accessed 7 May 2016].

Sex Education Forum (2003). Factsheet 30: Sex and Relationships Education Framework.

Sex Education Forum (2004). Factsheet 32: Sex and relationships education for children and young people with learning difficulties.

Smith, K., Wheeler, B., Pilecki, P. and Parker, T. (1995). The role of the pediatric nurse practitioner in educating teens with mental retardation about sex. Journal of Pediatric Health Care 9(2): pp.59-66.

Swango-Wilson, A. (2008). Caregiver perceptions and implications for Sex Education for individuals with intellectual and developmental disabilities. Sexuality and Disability 26: pp.167-174.

The Children's Learning Disability Nursing Team (2009). Puberty and Sexuality for children and young people with a learning disability [online]. Department of Health: NHS 
Leeds. Available at: http://www.leeds.gov.uk/docs/Puberty-and-Sexuality-PackSession1-4.pdf [Accessed 05 June 2016].

Tsinos, D. (2011). Learning Disabilities under the spectrum of counseling. Dissertation. TEI of Ioannina.

Van Dyke, D. C., McBrien, D. M., Siddiqi, S., and Petersen, M. C. (1998). Sexuality in Individuals with Down Syndrome. In: Rondal, J. A., Perera, J., and Nadel, L. (Eds) Down Syndrome: A Review of Current Knowledge, pp.33-47. London: Whurr.

Vygotsky, L. (1986). Thought and Language. (Rev.ed.). Cambridge, MA: MIT Press

Wolfe, P. and Blanchett, W. (2003). Sex Education for Students with Disabilities. Teaching Exceptional Children 36(1): pp.46-51.

Yonge, O. and Myrick, F. (2000). The journaling assignment: Issues and paradoxes. Available at: $\quad$ http://www.stlhe.ca/wp-content/uploads/2011/06/The-JournallingAssignment.pdf [Accessed 10 April 2016]. 


\section{Appendix A}

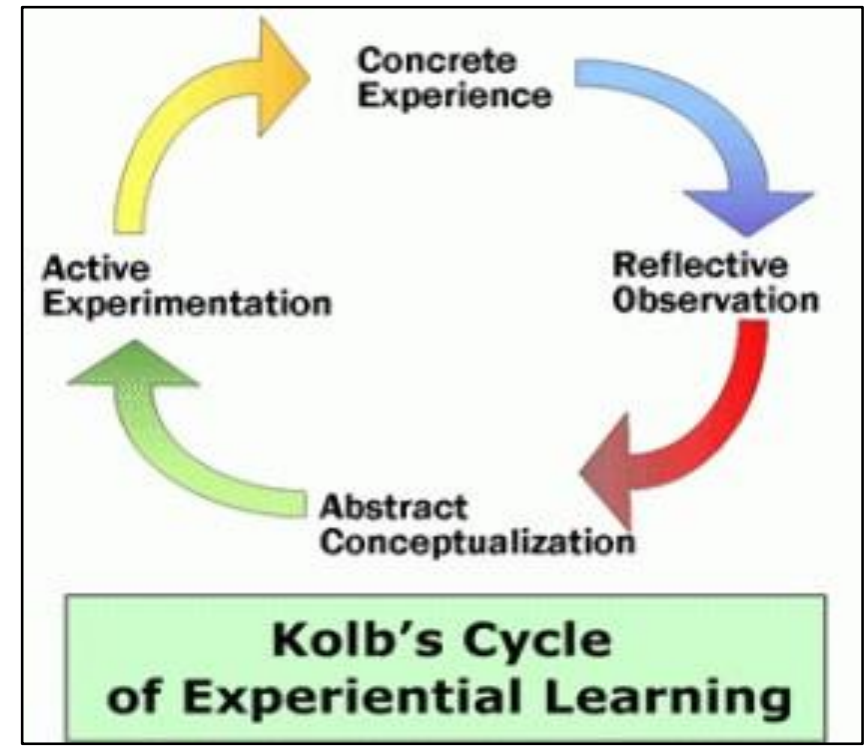

Source: Kolb, D. A. (1981) Learning styles and disciplinary differences. The modern American college pp. 232-255.

\section{Appendix B}

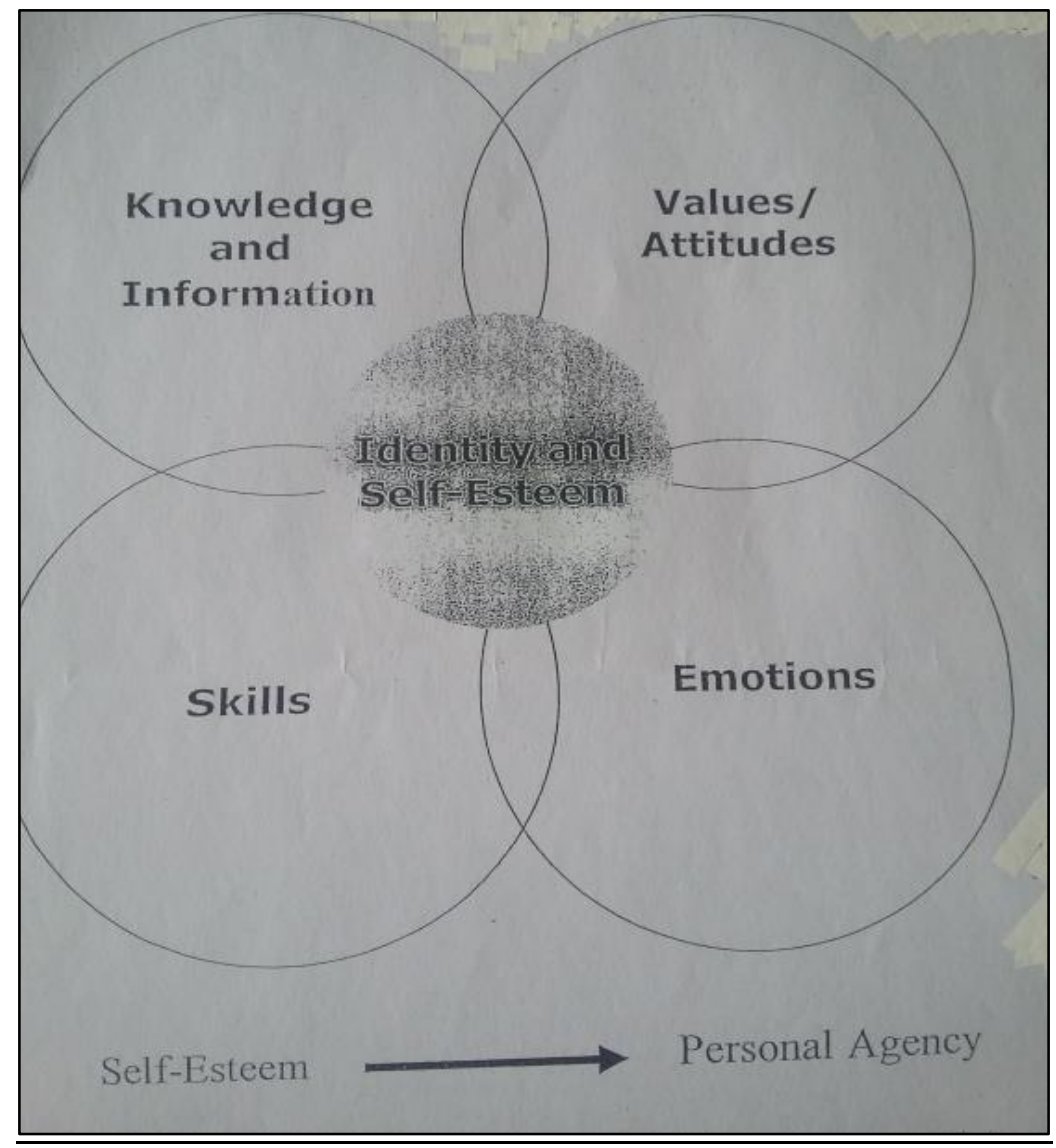

Source: Blake, S. and Laxton, J. (1997) Strides: A Practical Guide to Sex and Relationships Education with Young Men. London: fpa. 


\section{Appendix C}
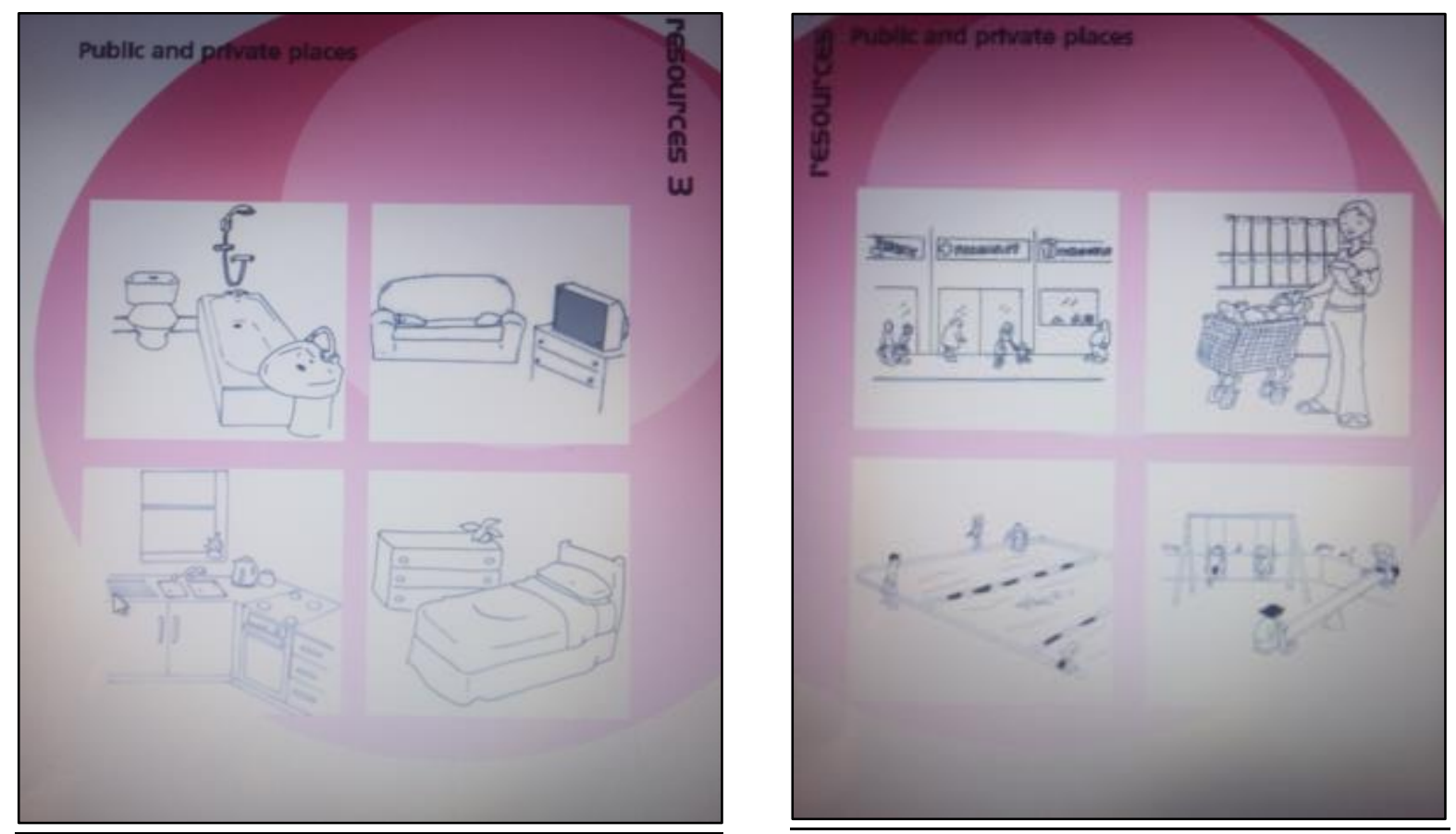

Source: The Children's Learning Disability Nursing Team (2009) Puberty and Sexuality for children and young people with a learning disability [online]. Department of Health: NHS Leeds.

Available at: http://www.leeds.gov.uk/docs/Puberty-and-Sexuality-Pack-Session1-4.pdf [Accessed 05 June 2016].

\section{Appendix D}

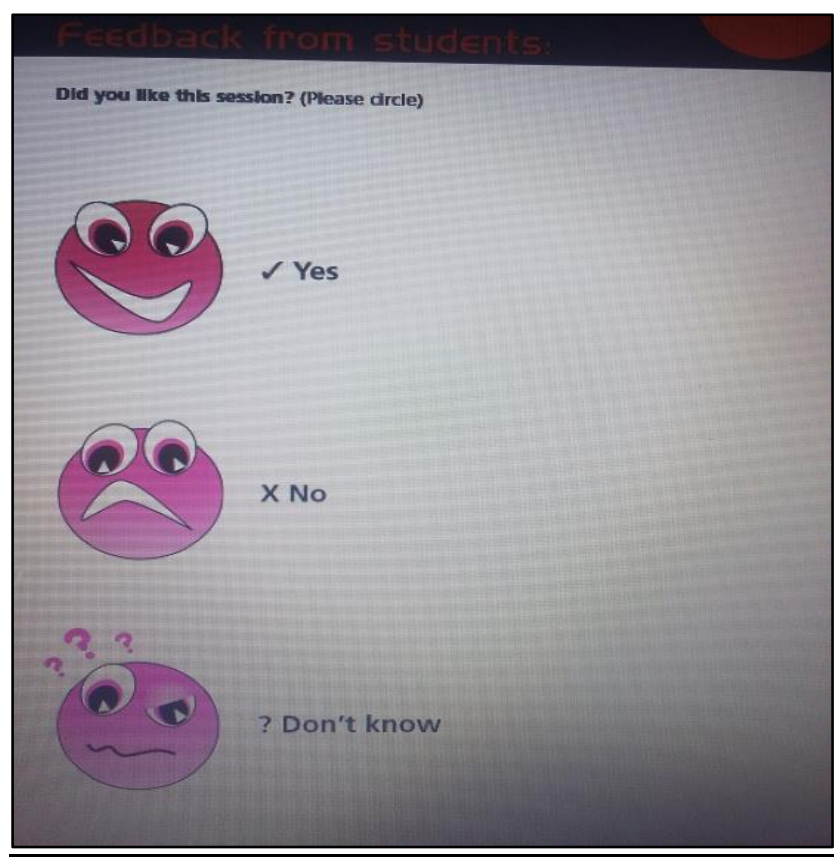

Source: The Children's Learning Disability Nursing Team (2009) Puberty and Sexuality for children and young people with a learning disability [online]. Department of Health: NHS Leeds.

Available at: http://www.leeds.gov.uk/docs/Puberty-and-Sexuality-Pack-Session1-4.pdf [Accessed 05 June 2016]. 
Creative Commons licensing terms

Authors will retain the copyright of their published articles agreeing that a Creative Commons Attribution 4.0 International License (CC BY 4.0) terms will be applied to their work. Under the terms of this license, no permission is required from the author(s) or publisher for members of the community to copy, distribute, transmit or adapt the article content, providing a proper, prominent and unambiguous attribution to the authors in a manner that makes clear that the materials are being reused under permission of a Creative Commons License. Views, opinions and conclusions expressed in this research article are views, opinions and conclusions of the author(s). Open Access Publishing Group and European Journal of Special Education Research shall not be responsible or answerable for any loss, damage or liability caused in relation to/arising out of conflict of interests, copyright violations and inappropriate or inaccurate use of any kind content related or integrated on the research work. All the published works are meeting the Open Access Publishing requirements and can be freely accessed, shared, modified, distributed and used in educational, commercial and non-commercial purposes under a Creative Commons Attribution 4.0 International License (CC BY 4.0). 